Supplement of Biogeosciences, 13, 4555-4567, 2016

http://www.biogeosciences.net/13/4555/2016/

doi:10.5194/bg-13-4555-2016-supplement

(C) Author(s) 2016. CC Attribution 3.0 License.

(c) (i)

Supplement of

\title{
Distribution of Arctic and Pacific copepods and their habitat in the northern Bering and Chukchi seas
}

\section{Hiroko Sasaki et al.}

Correspondence to: Hiroko Sasaki (hiro_sasaki@salmon.fish.hokudai.ac.jp)

The copyright of individual parts of the supplement might differ from the CC-BY 3.0 licence. 


\section{Supplementary materials}

Figure S1. Maximum density gradient $\left(10^{-3} \mathrm{~kg} \mathrm{~m}^{-1}\right)$ at each sampling station.

Figure S2. Horizontal distributions of temperature $\left({ }^{\circ} \mathrm{C}\right)$ averaged within the upper $\left(\mathrm{T}_{\mathrm{UPP}}\right.$, top panels) and the bottom ( $\mathrm{T}_{\mathrm{BO}}$, bottom panels) layers at each sampling station in 2007 (left panels), 2008 (middle panels) and 2013 (right panels).

Figure S3. Same as figure A2 but for salinity $\left(\mathrm{S}_{\mathrm{UPP}}\right.$ and $\left.\mathrm{S}_{\mathrm{BOT}}\right)$.

Figure S4. Same as figure A2 but for Chlorophyll- $a$ concentration (Chl $a_{\mathrm{UPP}}$ and Chl $\left.a_{\mathrm{BOT}}\right)$.

Figure S5. Climatological mean sea ice retreat date of 1991-2013.

Figure S6. The anomaly of sea ice retreat at all sampling locations in 2007, 2008 and 2013 based on daily passive microwave sea ice concentrations using a threshold of $40 \%$.

Figure S7. Correlation charts of with aTSR thresholds of $50 \%$ vs. 0-40\%. 

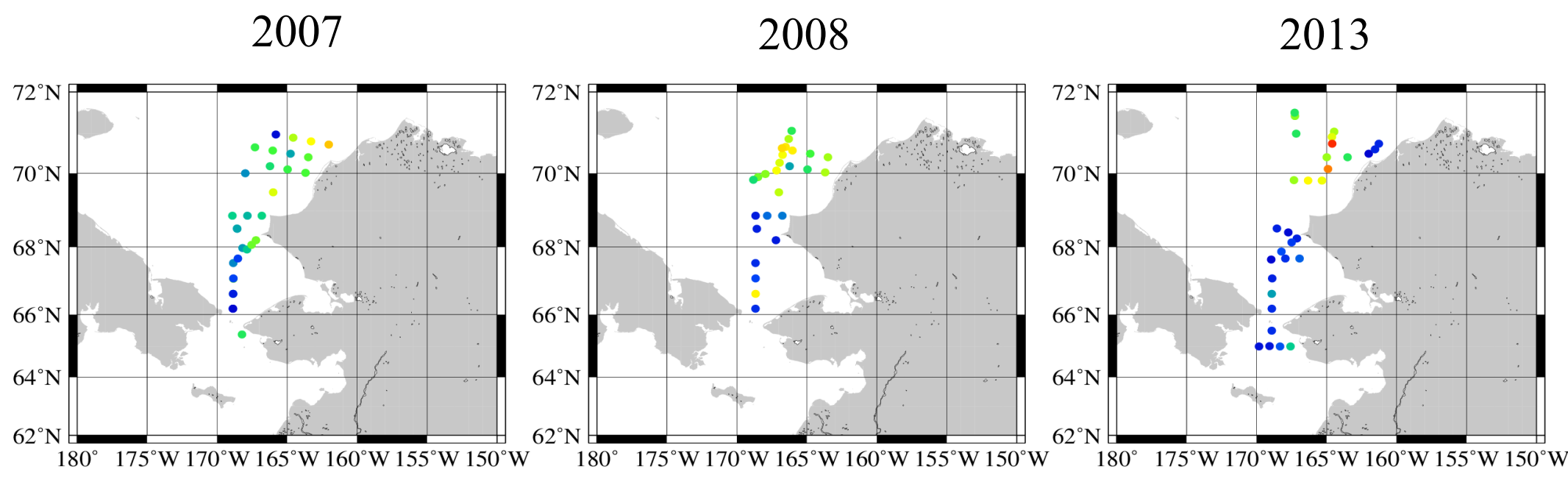

Density gradient $\left(10^{-3} \mathrm{~kg} \mathrm{~m}^{-1}\right)$

$\begin{array}{llllll}0 & 0.2 & 0.4 & 0.5 & 0.8 & 1.0\end{array}$

Figure S1 (Sasaki et al.) 

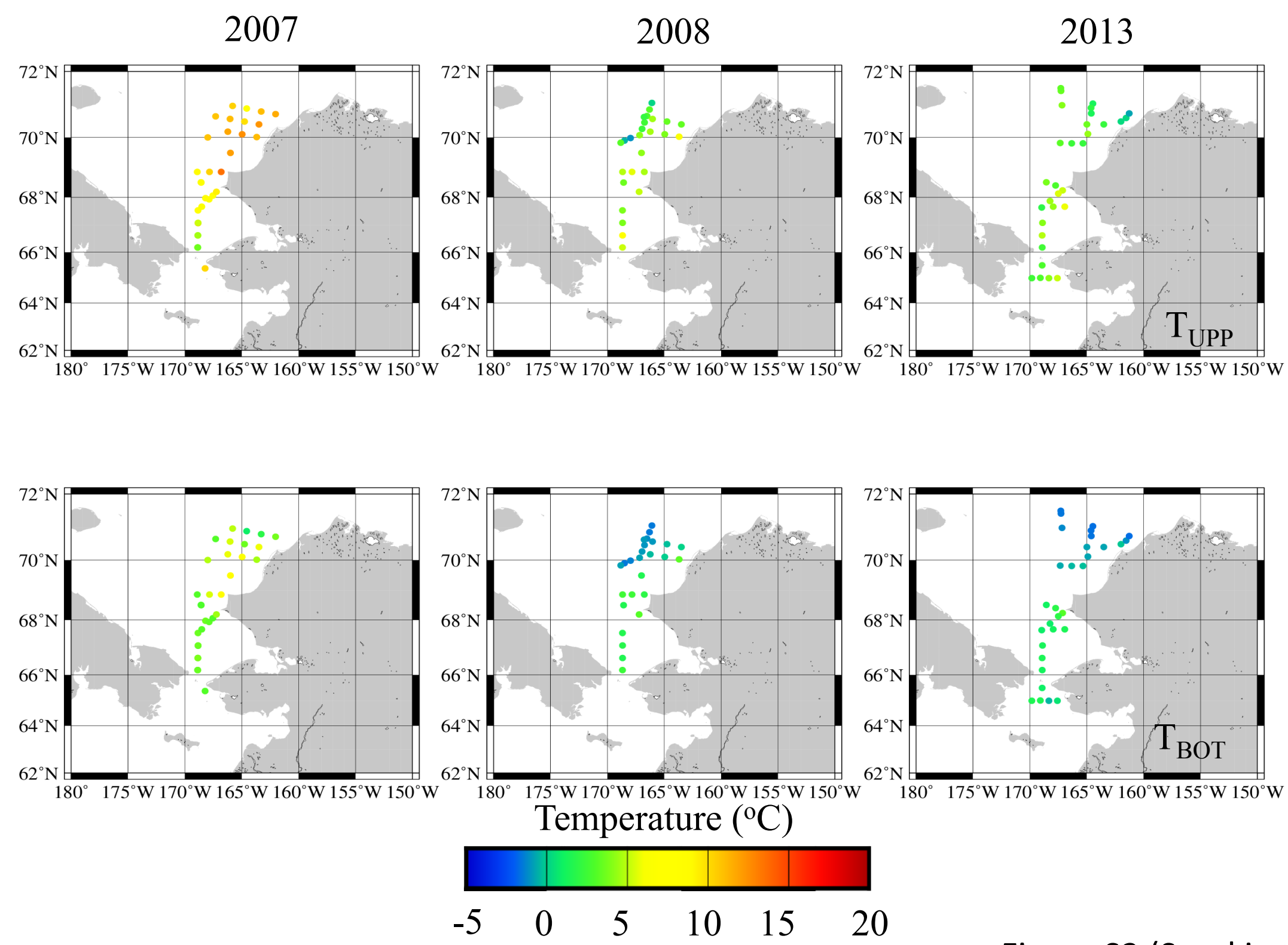

Figure S2 (Sasaki et al.) 

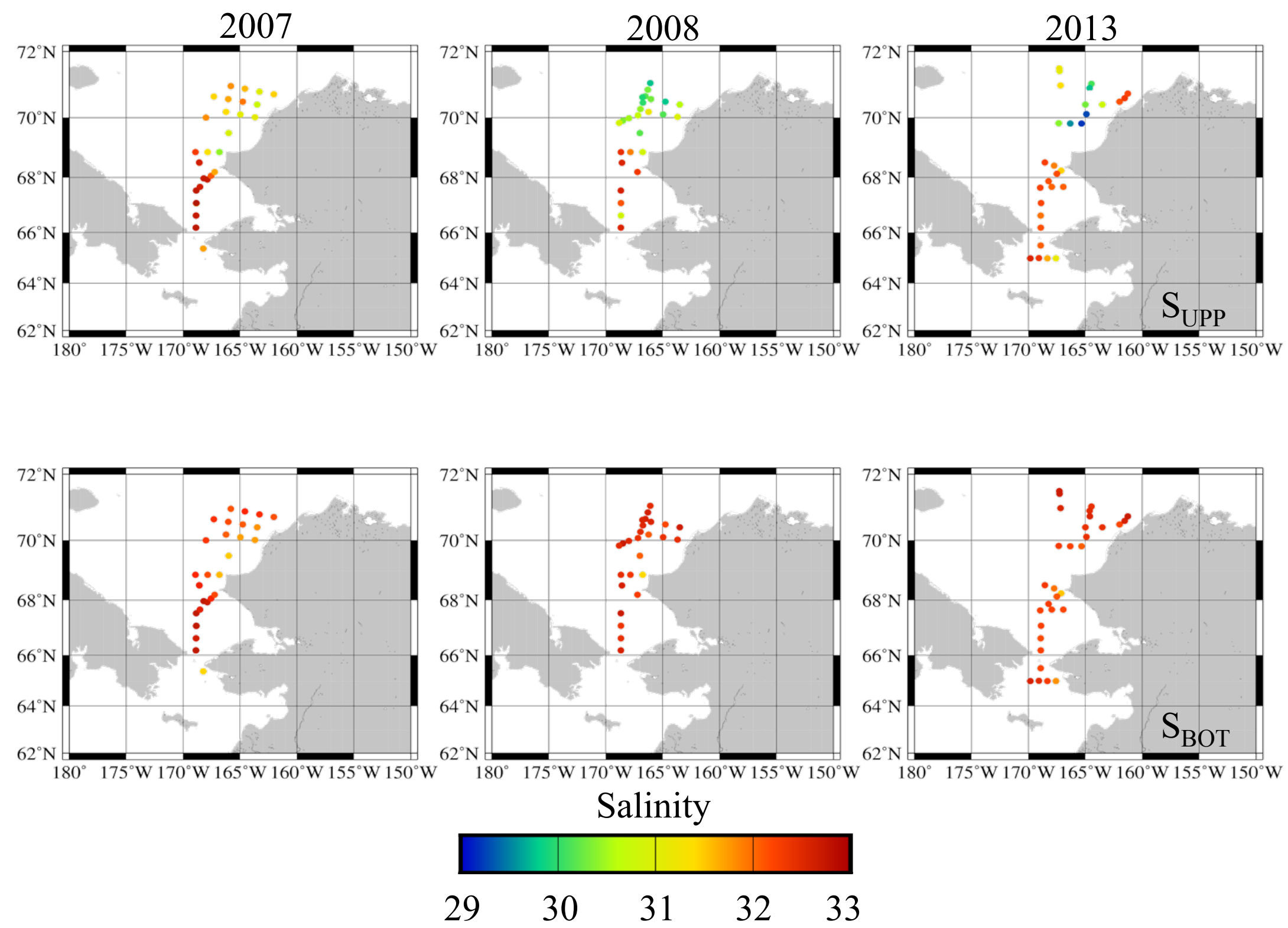

Figure S3 (Sasaki et al.) 

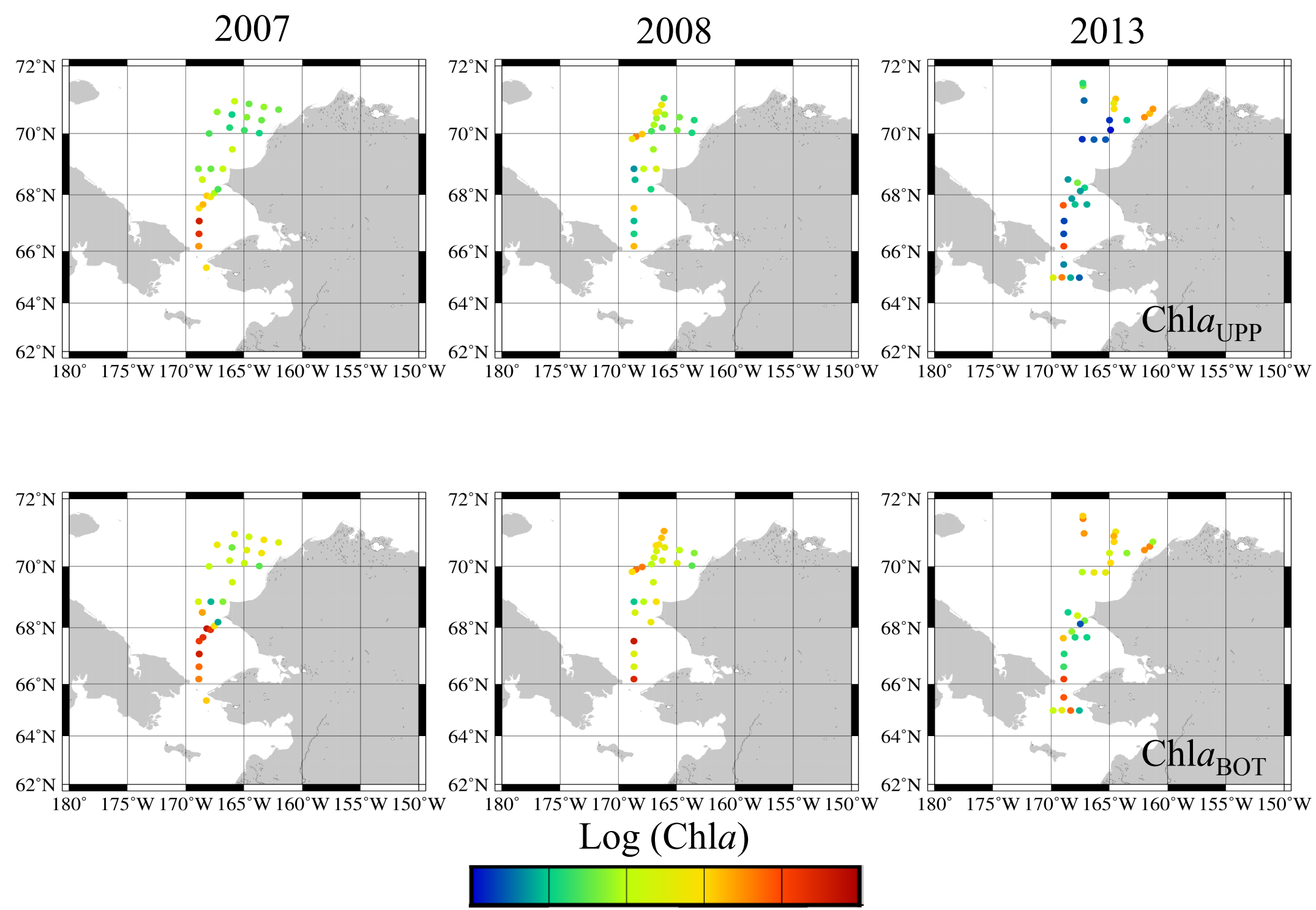

$\begin{array}{llllll}-1.0 & -0.5 & 0 & 0.5 & 1.0 & 1.5\end{array}$

Figure S4 (Sasaki et al.) 

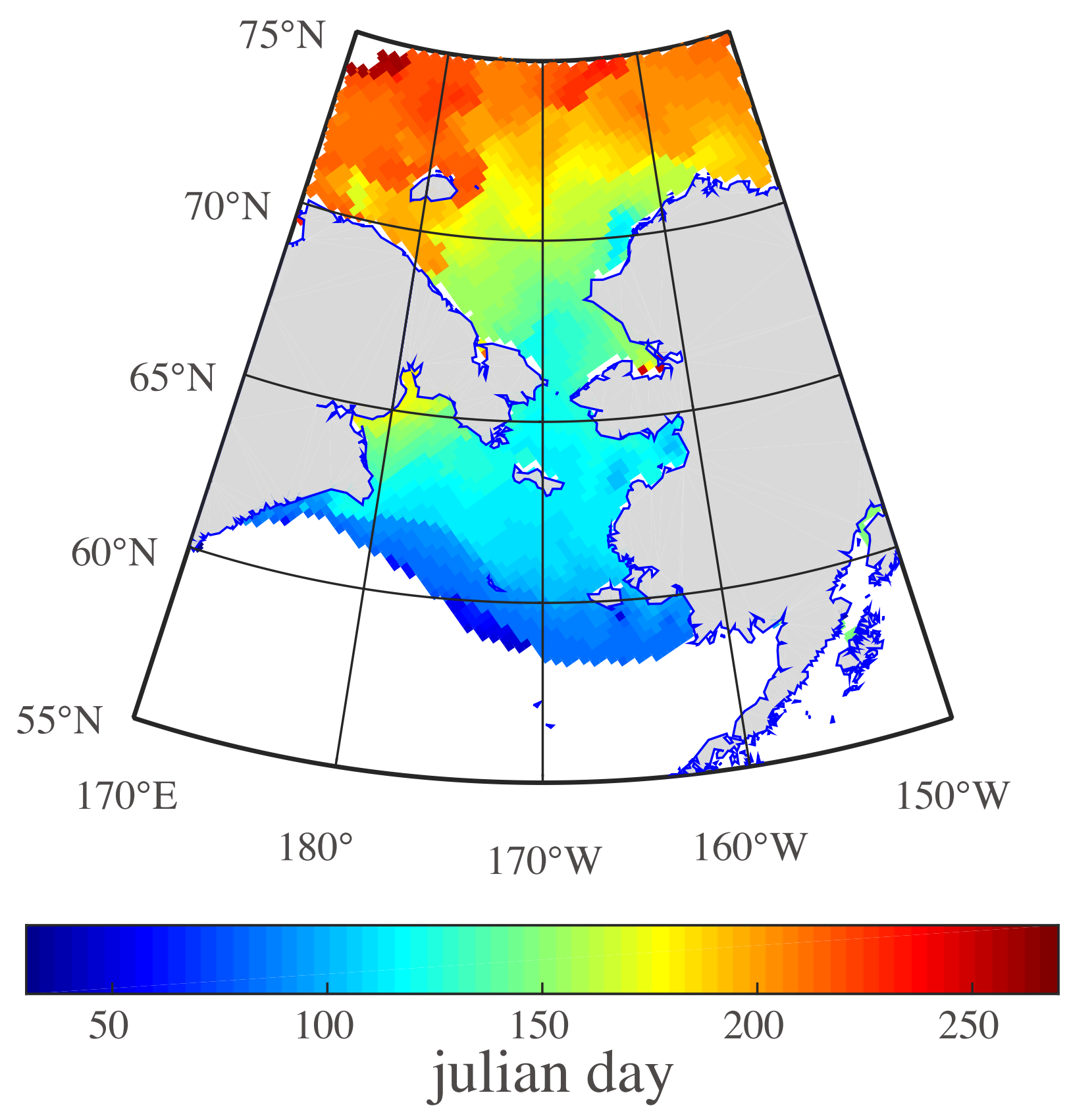

Figure S5 (Sasaki et al.) 


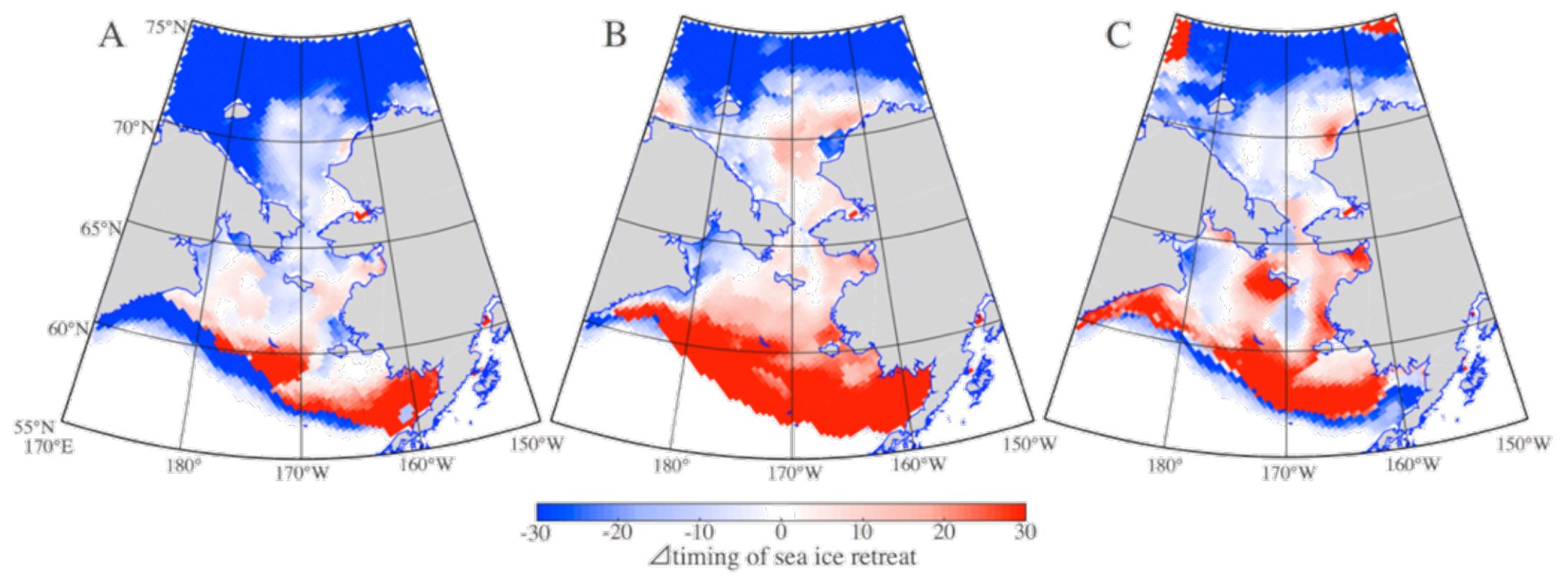

Figure S6 (Sasaki et al.) 

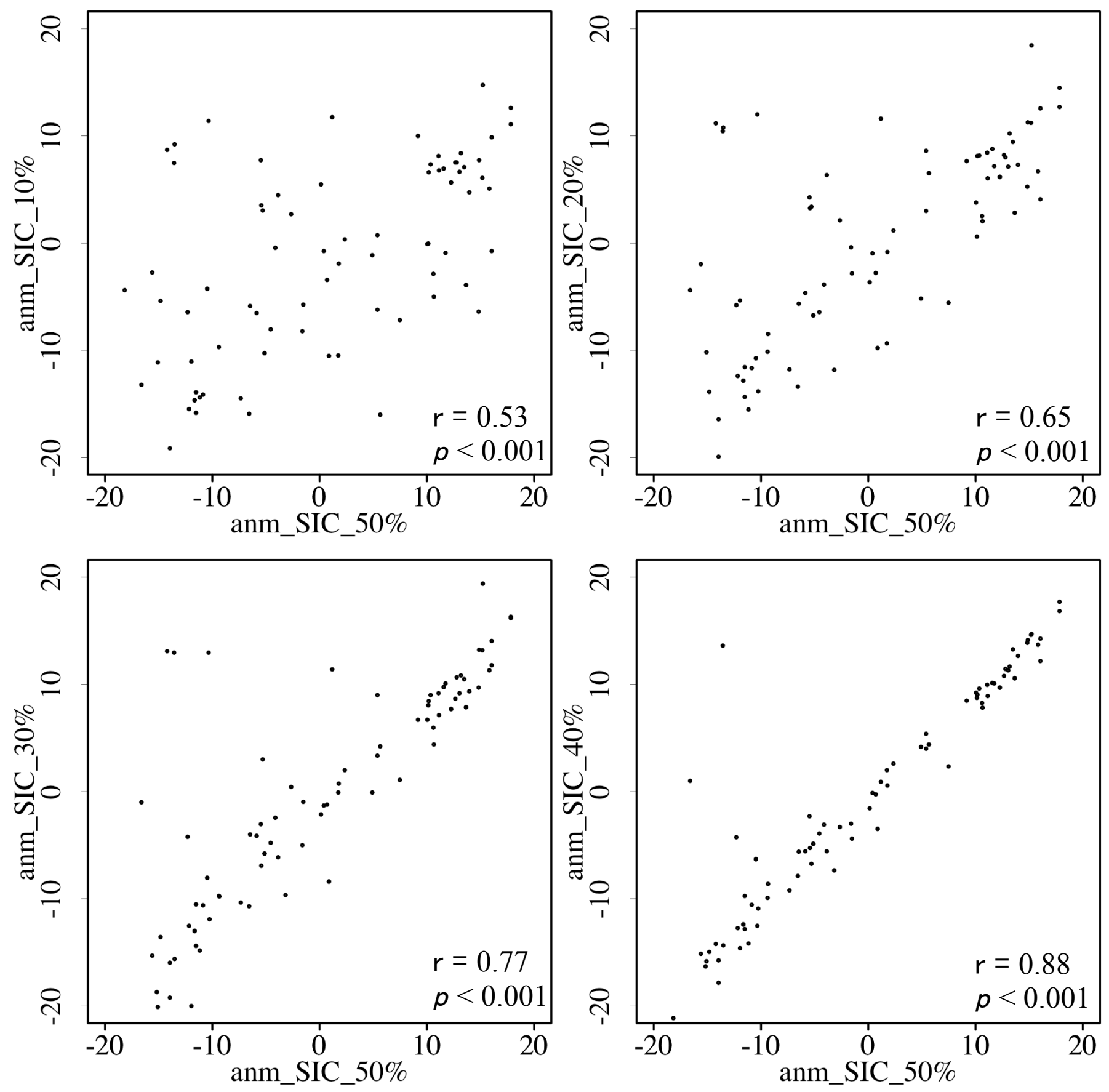

Figure S7 (Sasaki et al.) 